УДК $630 * 232.41$

DOI: $10.34220 / 2311-8873-2020-3-3-113-118$

ТИПЫ РАБОЧИХ ОРГАНОВ ОБОРУДОВАНИЯ ДЛЯ ВЫКОПКИ ПОСАДОЧНОГО МАТЕРИАЛА С ПОЧВЕННЫМ КОМОМ

Дручинин Д.Ю., Воскобойник М.Ю.

Федеральное государственное бюджетное образовательное учреждение высшего образования «Воронежский государственный лесотехнический университет им. Г.Ф. Морозова»

E-mail: druchinin.denis@ rambler.ru

Аннотация: Проведен анализ типов рабочих органов, используемых в серийно выпускаемом оборудовании для выкопки крупномерного посадочного материала с комом почвы. Оценены преимущества и недостатки дугообразных и сегментных ножей выкопочных машин с точки зрения условий работы, энергоемкости рабочего процесса и формы выкапываемого почвенного кома.

Ключевые слова: посадочный материал с комом почвы, выкопка саженцев, пересадка деревьев, выкопочное оборудование, дугообразный рабочий орган, сегментный рабочий орган, кинематика, энергоемкость.

\title{
TYPES OF WORKING TOOLS OF EQUIPMENT FOR LIFTING PLANTING MATERIAL WITH SOIL CLOD \\ Druchinin D.Yu., Voskoboynik M.Yu.
}

Federal State Budgetary Educational Institution of Higher Education «Voronezh State Forestry University. G.F. Morozova»

Email: druchinin.denis@ rambler.ru

Summary: An analysis of the types of working tools used in serially produced equipment for digging large planting material with a soil clod has been carried out. The advantages and disadvantages of arcuate and segmental knives of lifting machines have been evaluated from the point of view of working conditions, energy intensity of the working process and the shape of the soil clod dug out.

Keywords: planting material with a soil clod, plantlets lifting, replanting trees, lifting equipment, arcuate working tool, segment working body, kinematics, energy intensity. 


\section{Введение}

При выращивании крупномерного посадочного материала в лесных и декоративных питомниках важной операцией, от которой во многом зависит качество заготавливаемого растения, является его выкопка. Исследователи отмечают факторы, определяющие успешность выполнения данной технологической операции - необходимость подрезки корневой системы саженца и его кроны, сроки проведения выкопки, наличие водного стресса, размер почвенного кома, обеспечивающий минимальную потерю корней и т.д. $[1,2]$.

Для механизации трудоемких работ производственными предприятиями выпускаются различные модификации выкопочного технологического оборудования, которое отличается кинематическими особенностями и формой используемых подкапывающих рабочих органов [3, 4].

\section{Цель исследования}

Целью данной статьи является проведение обзора конструктивного исполнения используемых рабочих органов серийно выпускаемого оборудования для выкопки растений с комом почвы в древесных питомниках и заготовки деревьев в лесу.

\section{Материалы и методы}

При анализе конструкций выкопочных устройств установлено, что перспективными для применения являются подкапывающие рабочие органы в виде ковшей и скоб. Постоянные величины усилия и скорости их движения позволяют рассматривать процесс заглубления рабочих органов в почву как статический [5].

Технические особенности выкопочного оборудования во многом зависят от типа агрегатируемого с ним энергетического средства - различают машины, навешиваемые на трактор, погрузчик или экскаватор, и машины, имеющие специальное самоходное шасси.

В ограниченных условиях площади школьного отделения древесного питомника целесообразно применение малогабаритных самоходных выкопочных машин на специальном шасси. В то же время при заготовке крупномерного посадочного материала непосредственно на лесных площадях преимущество следует отдавать навесному оборудованию с мощным энергетическим средством.

В перспективных для применения в питомниках конструкциях самоходных мобильных выкопочных машин фирм «Pazzaglia» и «Holmac» распространено использование дугообразных ножей (рис. 1), обеспечивающих выкопку растений с комом почвы диаметром от 25 до 160 см [6, 7]. 

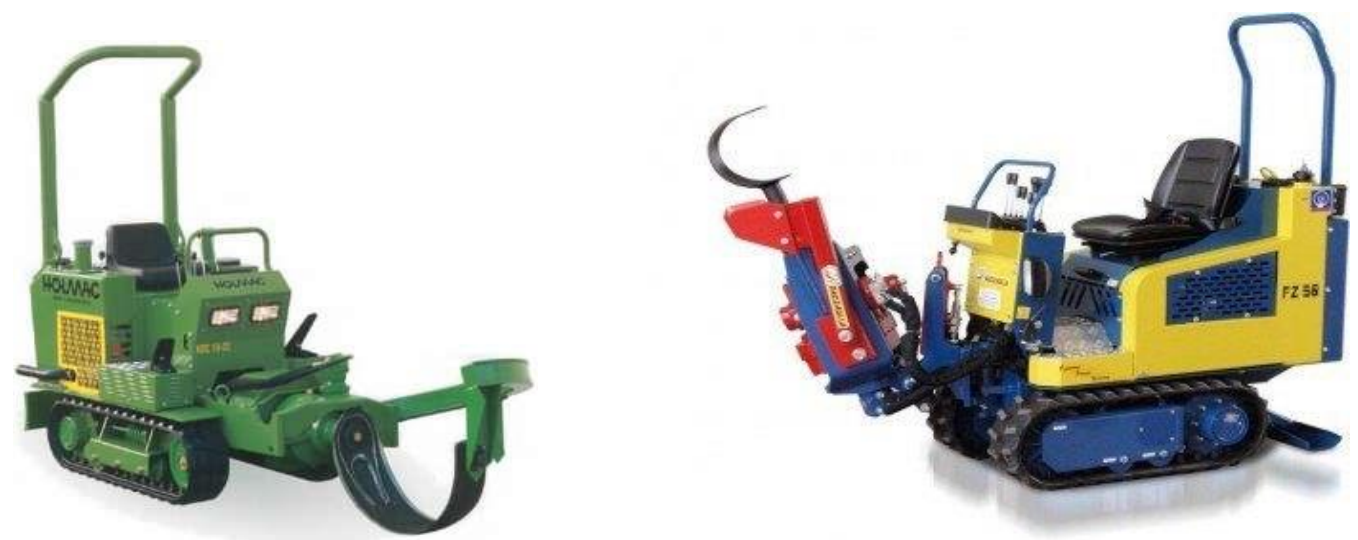

Рисунок 1 - Самоходное выкопочное оборудование для древесных питомников [6, 7]

Рабочий орган, имеющий гидравлический привод, размещается на вибрационной головке с целью использования при выкопке создаваемого ею специального эффекта - как отмечают исследователи, при приложении знакопеременных нагрузок снижается усилие на исполнительных механизмах за счет ослабления связывающих сил между элементами почвы. За счет малой величины площади поверхности подкапывающей скобы рабочий процесс данных машин характеризуется минимальным значением силы трения ножа о грунт. Однако применение данной техники с вибрационным эффектом предпочтительно на пластичных грунтах с высокой степенью влажности, так как на твердых почвах структура выкапываемого кома оказывается разуплотненной, что может привести к его разрушению при дальнейшей погрузке и транспортировке. На сохранности почвенного кома при работе на слабопластичных грунтах также отрицательно сказывается отсутствие поддерживающих его элементов в конструкции рабочего органа. Но при этом свободное состояние кома почвы позволяет упростить его упаковку в укрывной материал [4].

Разработка специального шасси положительно сказывается на компактности и мобильности технических средств данного принципа исполнения, однако ограничивает использование техники только лишь для операций выкопки посадочного материала. В то же время использование съемного оборудования, агрегатируемого с тракторами или погрузчиками, позволяет использовать данные энергетические средства на других работах после завершения периода посадочных работ.

Для заготовки крупномерных древесных растений в лесных условиях перспективен другой конструктивный принцип исполнения рабочих органов сегментный, который использует предприятие «Optimal Opitz» (Германия), вы- 
пускающее выкопочное оборудование трех модификаций [8].

Широко распространенная серия машин от Optimal 350 до Optimal 2200 оснащается ножами вогнутой формы, сходящихся в единой нижней точке. Форма выкапываемого кома почвы соответствует структуре более развитой корневой системы, тем самым, способствует лучшей приживаемости крупномерных растений после их пересадки (рис. 2).
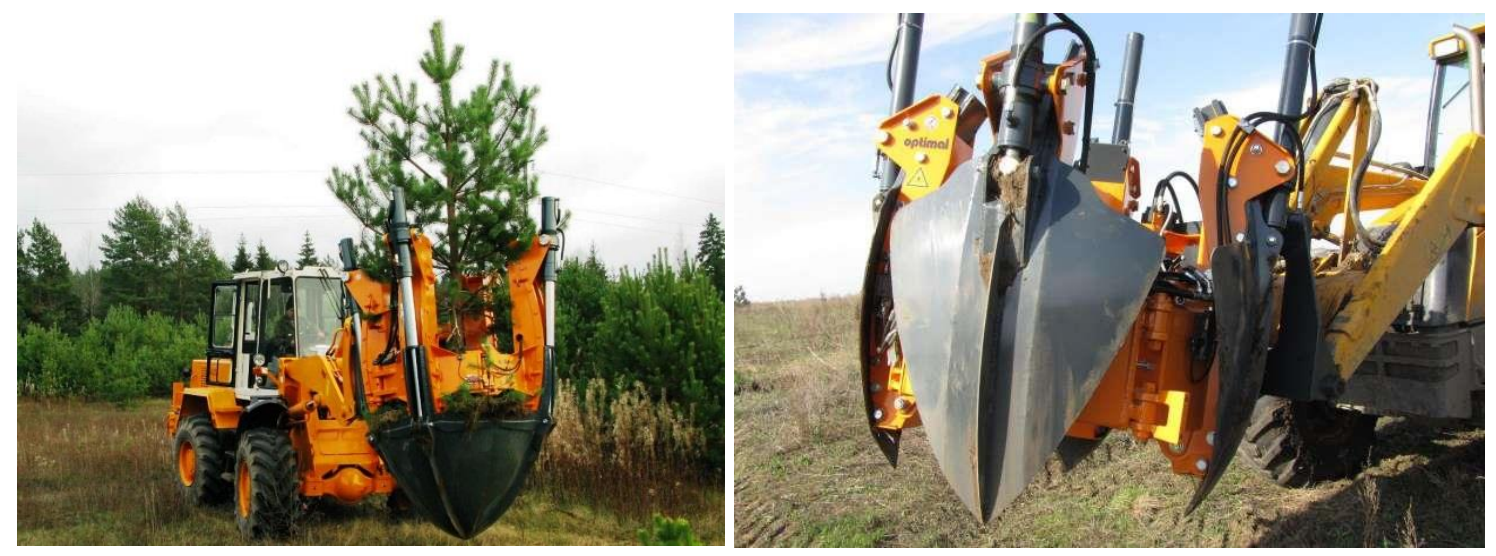

Рисунок 2 - Выкопочное оборудование с сегментными ножами вогнутой формы [8]

В то же время увеличение объема почвенного кома приводит к возрастанию его массы, что негативно сказывается на удобстве транспортировки растений. Подкапывающие ножи имеют большую в сравнении с дугообразными скобами площадь, что вызывает увеличение сил трения почвы о рабочие органы, а значит требует более мощный привод для такого оборудования, поэтому его обычно агрегатируют с тракторами или погрузчиками.

В отличие от «классической» лепестковой формы рабочего органа оборудование серии L-line имеет подкапывающий механизм с ножами прямой формы (рис. 3), которые не до конца смыкаются снизу, образуя при выкопке почвенный ком в виде перевёрнутого усечённого конуса [8]. Данные режущие элементы за счет прямолинейной кромки лезвия испытывают меньшее сопротивление при работе на плотных почвах.

Применение выкопочного оборудования рассмотренного принципа работы, подразумевающего поочередное смыкание сегментных рабочих органов, перспективно на площадях с почвенной структурой, имеющей слабую способность сохранения своей формы при механическом воздействии, ввиду полного охвата почвенного кома поверхностью ножей. 


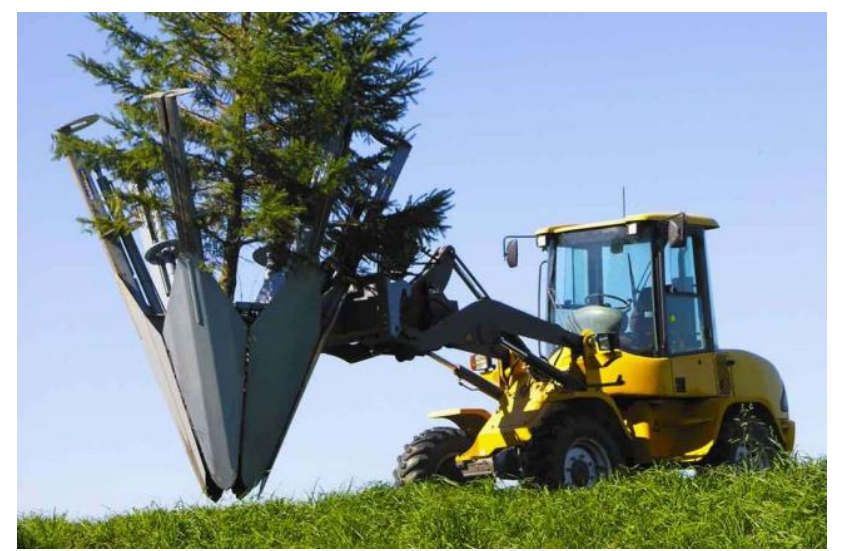

Рисунок 3 - Выкопочное оборудование с сегментными ножами прямой формы [8]

Техника серии P-Line имеет рабочий орган, состоящий из двух скоб сферической формы (рис. 4). За счет увеличенной площади скобы выкапываемый ком почвы, имеющий форму полусферы, надежно удерживается в устройстве, что упрощает его подъем и дальнейшее перемещение. Используемый принцип работы позволяет эксплуатировать машины на почвах легкого механического состава с целью сохранения цельного почвенного кома. Для снижения энергоемкости резания и качественного среза корней кромка лезвия скоб выполнена волнообразной. Глубина подкопки растения составляет до 32 см.

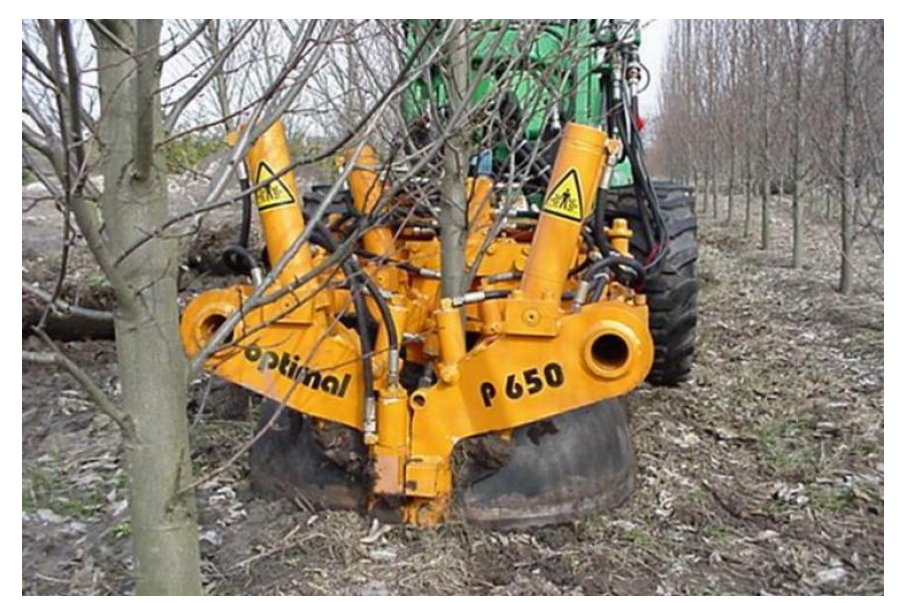

Рисунок 4 - Выкопочное оборудование со сферическим рабочим органом [8]

Фирма «Dutchman» (Канада) использует аналогичный конструктивный подход в создании рабочих органов выкопочного обрудования - в широком ассортименте машин используются сегментные прямые или изогнутые ножи, внедряемые в почву при помощи гидропривода. Различные модификации оборудования, размещаемого на базе грузовых автомобилей, позволяют осуществ- 
лять выкопку взрослых деревьев с диаметром кома почвы от 160 до 250 см с последующей перевозкой растений к месту посадки (рис. 5) [9].

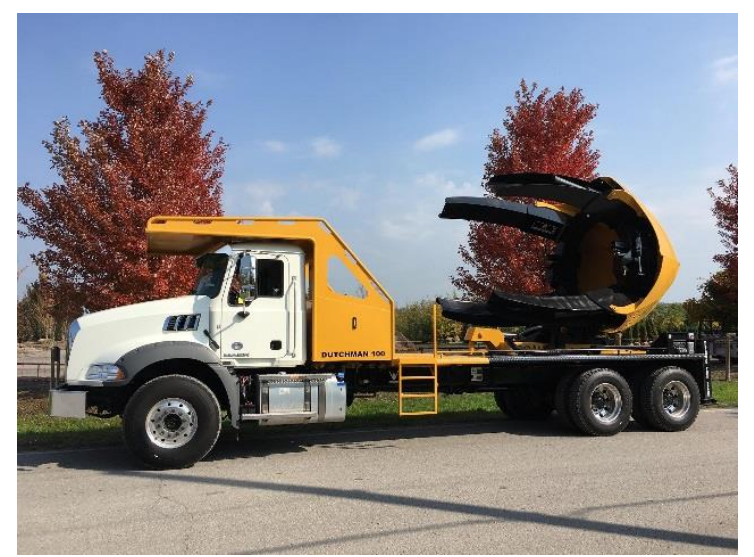

Рисунок 5 - Выкопочное оборудование фирмы «Dutchman» [9]

В то же время в выпускаемой данным предприятием технике реализуется и другой принцип конструктивного исполнения сегментных рабочих органов два криволинейных лезвия подкапывающего исполнительного механизма после смыкания в почве образуют ком в форме перевернутого усеченного конуса (рис. 6). Данное выкопочное оборудование предназначено для работы с низкорослыми древесными растениями и кустарниками в декоративных питомниках. Для удобства подъема и погрузки на транспортное средство оно может размещаться на базе манипуляторной установки.

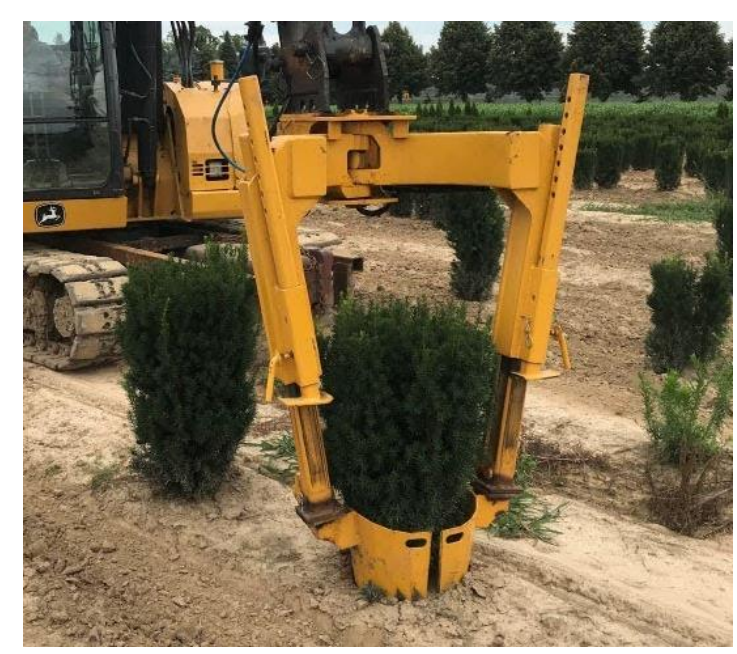

Рисунок 6 - Выкопочное оборудование фирмы «Dutchman» с рабочим органом в форме усеченного конуса [9]

Следует также отметить, что учеными предлагается различное конструктивное исполнение рабочих органов выкопочных машин в рамках регистриру- 
емых патентных документов по исследуемой тематике, однако они не получили широкого применения.

\section{Выводы}

Анализ используемых типов подкапывающих механизмов в конструкциях серийно выпускаемого выкопочного оборудования показал, что широкое применение в нем находят дугообразные и сегментные рабочие органы. Их конфигурация и кинематический принцип работы оказывают большое влияние на энергетические показатели процесса выкопки, форму и сохранность почвенного кома в целом, а также на технологию дальнейшей транспортировки выкопанного растения.

Немаловажным моментом является учет почвенных характеристик места заготовки древесных растений - на менее пластичных грунтах во избежание некачественного формирования глыбки целесообразно использование рабочих органов с полным охватом поверхности выкапываемого почвенного кома.

Для работ по заготовке крупномерного посадочного материала в школьных отделениях лесных и декоративных питомниках целесообразно использование малогабаритных и маневренных выкопочных машин на специальном самоходном шасси, оснащенных менее энергоемким дугообразным рабочим органом. Минимальный контакт подкапывающей скобы с поверхностью почвенного кома упрощает его выгрузку и упаковку в укрывной материал, но для последующей перевозки растения требуется дополнительное транспортное средство.

В то же время выкопку взрослых деревьев необходимо осуществлять машинами с сегментными рабочими органами, имеющими мощный привод. Такая конструкция подкапывающего механизма позволяет заготавливать великовозрастные растения с более объемным комом почвы, а значит, выкопать развитую корневую систему растения с меньшими повреждениями. Размещение оборудования на тракторе, погрузчике или грузовом автомобиле дает возможность упрощенной доставки крупномерного саженца к месту посадки этим же энергетическим средством.

\section{СПИСОК ЛИТЕРАТУРЫ}

1 Дручинин, Д. Ю. Концепция создания технического средства для использования посадочного материала с комом почвы при озеленительных и лесовосстановительных работах / Д. Ю. Дручинин, М. В. Драпалюк // Агролесомелиорация в 21 веке : состояние, проблемы, перспективы: материалы 
Международной научно-практической конференции молодых ученых и специалистов 26-28 октября 2015 г. - Волгоград, 2015. - с. 83-87.

2 Pryor M. Mature tree transplanting: Science supports best management practice / M. Pryor, G. Watson // Arboricultural Journal. 2016. - 38(1). - P. 2-27. DOI : 10.1080/03071375.2016.1157401.

3 Дручинин, Д. Ю. Зарубежные технические средства для выкопки посадочного материала с почвенным комом / Д. Ю. Дручинин, Е. В. Поздняков, С. В. Малюков, Д. С. Сергиенко // Актуальные направления научных исследований XXI века : теория и практика : сборник трудов по материалам международной заочной научно-практической конференции. - Воронеж, 2015. - № 9-3 (20-3). - C. 49-52.

4 Лысыч, М. Н. Обзор современных машин для выкопки крупномерных деревьев с почвенным комом / М. Н. Лысыч, М. Л. Шабанов, Н. М. Очеретяный // Актуальные направления научных исследований XXI века : теория и практика : сборник трудов по материалам международной заочной научно-практической конференции. - Воронеж, 2017. - № 1 (27). - С. 146-150.

5 Грушанский, О. А. Исследование технологии и основных параметров рабочего органа машины для посадки крупномерных деревьев с комом земли : автореф. дис. ... к-та техн. наук : 05.20.01 / О. А. Грушанский. - Киев, 1994. - 30 с.

6 Pazzaglia S. r. 1. Режим доступа : https://pazzaglia.it/ - Загл. с экрана.

7 Holmac - машины для питомников растений. Режим доступа : https://holmac.ru/ - Загл. с экрана.

8 Optimal-Vertrieb Opitz GmbH. Режим доступа : https://www.opitz-optima$\underline{1 . c o m /}$ - Загл. с экрана.

9 Dutchman Industries Inc. Режим доступа : https://www.dutchmantreespade.com/ - Загл. с экрана. 